\title{
TRAJETÓRIA DA PELE: TEATRO E EDUCAÇÃO PENITENCIÁRIA EM MACAPÁ ${ }^{1}$
}

\author{
Emerson de Paula Silva \\ Frederico de Carvalho Ferreira \\ Mayara Caroline da Costa Marques
}

\section{INTRODUÇÃO}

Este capítulo configura-se como um relato do processo de inclusão do Teatro através de oficinas desenvolvidas na Coordenadoria da Penitenciária Feminina (COPEF) e no Instituto de Administração Penitenciária do Amapá (IAPEN), localizado na cidade de Macapá-AP, capital do Estado do Amapá. O projeto contemplou os homens presos e as mulheres presas do sistema penitenciário amapaense. Mas neste trabalho, abordaremos sobre as oficinas realizadas apenas na COPEF.

Numa escrita composta por várias mãos, procuramos abordar a trajetória do projeto, a trajetória dos/das participantes - proponentes e alunos(as) - e a trajetória construída a partir destes caminhos cruzados de múltiplas peles. São estas trajetórias que serão agora desveladas neste texto.

O projeto de extensão Teatro e Inclusão: Ressocialização através da Arte realizou oficinas de teatro com a participação de pessoas em situação de cárcere, que estavam custodiadas no sistema penitenciário amapaense, coordenado por Ferreira (2017). A equipe do projeto buscou potencializar a linguagem teatral como estimuladora da fruição estética para construir metodologias e materiais para as aulas das oficinas.

A iniciativa da ação extensionista surgiu a partir de aproximação, em 2017, entre a equipe do projeto de pesquisa Políticas Públicas para Educação Penitenciária no Amapá: Por uma implantação de Programa Governamental, coordenado por Vasquez a partir de 2012 e vinculado ao Grupo Políticas Públicas, Educação Inclusiva, Tecnologia Assitiva e Saúde Coletiva - PEPITAS e os membros do Núcleo de Estudos em Espaços Culturais, Deliberativos e Inclusivos - NECID. Ambos os projetos são registrados nos Departamentos de Extensão e de Pesquisa da UNIFAP, no Campus Marco Zero do Equador.

${ }^{1}$ DOI: $10.29388 / 978-65-86678-21-5-f .101-112$. 
Além disso, o projeto de extensão integrou o Programa de Cultura da UNIFAP - PROCULT, ligado ao Colegiado do Curso de Teatro - CCT, o qual contou com apoio do Núcleo de Acessibilidade e Inclusão da Pró-Reitoria de Extensão e Ação Comunitária - NAI/PROEAC/UNIFAP, nas primeiras ações de extensão.

As metodologias utilizadas nas aulas das oficinas propõem auto-descoberta, auto-percepção e exploração cognitiva, corporal e psicomotora. O objetivo do projeto foi realizar oficinas de teatro para analisar de forma teórica e prática o Teatro/Educação, cujas ações extensionistas foram desenvolvidas no período de abril até dezembro de 2017.

\subsection{O projeto de extensão e seus apoiadores}

O presente artigo também registra as experiências da UNIFAP sobre a temática, tendo esta ação extensionista dialogado com o Projeto Político-Pedagógico do Curso de Licenciatura em Teatro a partir da disciplina Estágio Supervisionado V (PALHANO; OLIVEIRA; COSTA, 2012), que propõe o contato dos licenciandos em espaços não escolares, o que intensificou a discussão sobre Teatro e Comunidade. Além de gerar uma experiência extensionista com a comunidade universitária e externa, e ainda, o impacto direto na formação acadêmica, enquanto agente transformador da realidade, estímulo à aprendizagem e também à cidadania.

A equipe do projeto de extensão procurou debater sobre a inclusão a partir da cultura na UNIFAP, apresentando o seu conceito e buscando soluções para tornar a cultura acessível, democrática e promotora da inclusão social às pessoas privadas de liberdade, o que nos faz ampliar o olhar para uma área de conhecimento que discute as potencialidades humanas em seus vários contextos e ambientes.

Neste projeto extensionista, consideramos as limitações e as possíveis restrições de participação das pessoas em situação de cárcere nas oficinas de teatro. No contexto de espaço não escolar, como o ambiente carcerário, a questão da coexitência da cultura escolar e da cultura prisional e sua relação entre os sujeitos que compõem a comunidade escolar-prisional no contexto da educação penitenciária no Estado do Amapá e com a prisonização (VASQUEZ, 2013), foi um dos temas debatidos pela equipe do projeto na UNIFAP.

$\mathrm{O}$ referido estudo nos movimentou a refletir sobre os aspectos que impedem ou dificultam a participação das pessoas privadas de liberdade a ter aces- 
so à cultura em geral e procuramos registrar vários olhares e realidades existentes, e possíveis de modificação através das oficinas de teatro.

Nesta perspectiva, também contribuiu com os debates entre os membros da equipe do projeto, os livros Pedagogia da Autonomia e Pedagogia do Oprimido de Freire $(1997,1994)$, além da metodologia do Teatro-Educação proposta por Boal (1999) e Spolin (2007), cujas discussões encontram-se nas obras Jogos para atores e não atores e Jogos Teatrais para a sala de aula, que subsidiam a prática pedagógica na execução das oficinas de teatro. E ainda, o livro Teatro a partir da comunidade de Ligiero (2003) e a pesquisa que enfoca os dilemas do Teatro na Prisão de Concílio (2006), subsidiaram também as temáticas e os exercícios que foram trabalhados nas aulas semanais no espaço prisional.

O espaço de atuação do projeto foi a Escola Estadual São José, gerenciada pela Secretaria de Estado da Educação - EESJ/SEED e localizada dentro da COPEF/IAPEN, cujo seu endereço é Rodovia Duca Serra, KM 07, s/n, Cabralzinho, na cidade de Macapá.

As aulas de teatro aconteceram durante a disciplina de Arte, com a supervisão da professora responsável desta área de conhecimento da EESJ.

\subsection{O teatro como parceiro no processo (des)civilizador}

Iniciamos este tópico do artigo de relato de experiência, considerando que "A escola básica, tradicional, disciplinadora, repleta de reminiscências "militarescas" e por vezes caracterizada como um depósito de pessoas, permanece estruturada na fragmentação dos espaços de convivência social, na separação seriada por idade e na importância de uma disciplina desmedida [...]" (FERREIRA, 2016, p. 6), reverberando esse aprisionamento disciplinar por meio do controle coercitivo na sociedade.

Apesar da cultura "escola-exílio" é possível levantar âncora rumo a um lugar de descobertas, de experiências, de vivências e de prazer. No entanto, o que separa a escola-exílio da escola básica?

A fim de compreender essa dissonância, entender como esse pensamento de aprisionamento ainda nos envolve e nos entorpece, recorremos ao livro Vigiar e Punir: O nascimento da prisão de Foucault (1999), para falarmos sobre o processo de escolarização.

Um dos maiores interesses de Foucault foram os mecanismos de controle estabelecidos pelas instituições de sequestro, cuja pesquisa apresentou uma abordagem inovadora sobre a história da prisão na França. $\mathrm{O}$ autor analisou os processos disciplinares, como escolas, prisões e hospícios, e identificou como 
elas terminavam por controlar aqueles que eram colocados nestes lugares por meio da imposição de padrões de conduta ditos normais. Submetida à ação externa, mentes e corpos humanos poderiam ser moldados por diversas instituições sociais.

Apesar dessas instituições promoverem proteção e assistência aos indivíduos, nelas também se inseririam mecanismos de controle baseados na ameaça de punição. E ainda, segundo Foucault (1999), os mecanismos punitivos teriam como papel trazer mão de obra suplementar, constituindo uma escravidão "civil", ao lado da que é fornecida pelas guerras ou pelo comércio.

A área da educação foi um dos destaques das análises do filósofo. Ao estudar o papel das escolas e das ideias pedagógicas, Foucault identificou ações de vigilância e adestramento do corpo e da mente, ou seja, formas de exercer o poder e produzir a sociedade disciplinar. Neste sentido, escolas, hospícios e prisões seriam instituições de sequestro, onde os indivíduos seriam retirados de seu espaço social e internados durante um longo período a fim de moldar sua conduta e disciplinar seu comportamento.

Acerca das prisões, Resende (2011) ressalta que, sendo a prisão uma instituição em que a "captura" da existência do indivíduo em todos os seus aspectos é exacerbada, enquadrando-o num esquema totalizante de reformulação de sua existência, chega-se ao ponto de ele próprio restringir sua vida ao tempo de estar preso. Para Foucault (1989), a disciplina seria o instrumento de dominação e controle dedicado a excluir ou domesticar os comportamentos divergentes.

A escolarização, assim como a medicalização e o aprisionamento, surgiu a partir de uma necessidade disciplinar que possibilitasse "a produção de uma tecnologia de controle" (VEIGA, 2002, p. 91).

Para Foucault (1981, p. 106), a disciplina é antes de tudo a análise do espaço como um dos elementos que constituem a noção de disciplina. É a individualização pelo espaço, a inserção dos corpos em um espaço individualizado, classificatório e combinatório. Partindo desse pressuposto, entende-se que a escolarização não está imbrincada somente em questões de produção e disseminação do saber, mas também na efetivação das relações de poder. Assim sendo, compreende-se a segmentação e a fragmentação do processo escolar como argumento tradicionalista, que busca o aumento de uma sociedade servil.

Compreende-se que a sociedade é baseada, então, em um processo cíclico de alterações constantes das relações de poder, que ora se encontram equilibradas e logo em seguida se desequilibram mediante tensões de controle. Percebe-se, neste ponto, uma espécie de rede de conexões que se apropria de 
uma dinâmica circular e espiral de tomadas e retomadas de posições e que subsidiem tensões constantes. Segundo Elias (1994, p. 23), “essas cadeias não são visíveis e tangíveis como grilhões de ferro. São mais elásticas, mais mutáveis, porém não menos reais e, decerto, não menos fortes".

O processo civilizatório instituído pela escolarização, mergulhado na homogeneização da sociedade, tornou a escola o espaço de defesa da supremacia masculina e de etnia branca, prevalecendo a importância da consolidação do núcleo familiar, criação de modelos de conduta de acordo com a idade, sempre revelando virtudes baseadas na inteligência, responsabilidade e competitividade como premissas de civilidade.

Vivemos ainda em uma sociedade que continua excluindo aquele que é diferente: o preso, o louco, o ocioso, por perderem ou fugirem do controle, acredita-se que perturbam a ordem do espaço social. Percebe-se que a instituição escolar permanece com o intuito de moldar a conduta e disciplinar o comportamento do indivíduo, com fim de inseri-lo no espaço social. A sociedade, de maneira geral, cria constantemente técnicas de controle das populações e de coletividade via sistemas de foto e vídeo, não somente por câmeras como também por satélite.

Temos, atualmente, uma sociedade que é capaz de se autocontrolar com tecnologias cada vez mais sofisticadas, utilizando inclusive o espaço sideral. Retomando o texto de Veiga (2002, p. 103), poderíamos pensar na construção de uma ação educativa que se fizesse em outras redes, nas quais fios diferenciados e múltiplos tecessem a trama do bordado e pela multiplicidade de olhares que um bordado nos permite visualizar.

O sentimento de aprisionamento e autocoerção imposto por diversos setores e instituições sociais, a sensação de punição iminente e o medo constituído e internalizado ao longo da história da sociedade, tão presente na instituição escolar, nos faz repensar questões sobre a dificuldade em se estabelecer relações mais humanas na escola e como esse processo educacional humanizante pode interferir positivamente diante da violência e da evasão escolar.

Numa proposta de inversão do controle instituído na escola, como um mote para a transgressão deste processo civilizador, propusemos, artisticamente falando, uma iniciação estética através do Teatro junto a Escola instalada na Penitenciária de Macapá, no sentido de possibilitar mecanismos de redescoberta do prazer e de constituir no espaço escolar, um ambiente de troca, de experiência e de formação pelo sensível.

A presença da instituição escolar dentro da prisão contribui de certa forma para uma quebra em alguns pressupostos sobre estas instituições, pois 
provoca reflexões em relação a alguns aspectos anteriormente mencionados. Nesse contexto, levar o Teatro à Educação Penitenciária é potencializar momentos de apreciação estética e criação artística individual e coletiva no campo da Arte/Teatro como recurso de encontro para potencializar a autonomia e a sensibilidade no contexto escolar prisional.

\section{RELATOS DAS TRAJETÓRIAS DAS NOSSAS PELES}

Pensando no projeto e nas trajetórias descobertas e nas que foram propostas após o percurso caminhado, se faz importante, para os pesquisadores, trazerem uma parte da memória de seus percursos que possui relação direta com nossa formação identitária explicitando como os questionamentos aqui apresentados estão inscritos na trajetória de nossa pele.

Três pessoas envolvidas, três visões diferentes de um mesmo espaço. Pela potencialidade daquilo que fica impregnado na pele de cada pessoa, trazemos os relatos da forma como eles se dão: "Um olhar feminino de uma aluna em construção de seu corpo de professora".

Em 01 de dezembro de 2017, no horário vespertino, estiveram presentes na COPEF, a equipe da extensão universitária. Porém, nesta data, a aula foi cancelada sem aviso prévio para o grupo de teatro, pois ocorreram revistas nas celas, o que restrigiu a liberação das estudantes em decorrência dos procedimentos de segurança da administração penitenciária. Neste horário, realizamos uma reunião com a coordenação e os professores da EESJ para avaliar a execução do projeto, do que foi aprendido pelas participantes e pelo próprio grupo. Também aproveitamos o momento para questionar os/as professores/as sobre o que pensavam desta extensão universitária.

O primeiro professor que falou, lembrou do dia que foi mais teóricoreflexivo, do contato que a prática promoveu nesta relação de estreitamento, em que ele conseguiu ver três momentos neste processo, teórico, prático, e reflexivo, e destacou: "É extremamente importante conhecer o corpo, não só do movimento, mas, saber administrar o corpo em diferentes situações" (Professor A, 2017).

Percebe-se que este primeiro posicionamento só foi possível por causa das mudanças que puderam ser observadas nas mulheres, o que se percebeu quando ele falou: "Interessante elas mencionarem a expectativa da sexta-feira, vi que estava sendo bom, estava fazendo bem para elas" (Professor A, 2017). Esta fala é o princípio de uma visão sensível em torno da postura delas, porque 
compreende um estado diferente de emoção e de significação enquanto pessoas.

Um professor comentou que esteve presente para observar uma aula e até sentiu vontade de interagir na aula prática. Isso pode ser levado em conta, porque ele mesmo se pergunta e sugere: "Como isso reflete no dia-a-dia delas? Sugiro que se peça sugestão delas. O que elas poderiam sugerir?" (Professor B, 2017).

O professor coordenador do projeto de extensão relatou que: "Começamos a ouvir as sugestões delas a partir dos protocolos individuais de avaliação das aulas e de como a música, a dança começaram a aparecer nos desenhos, que elas protocolavam no fim das aulas" (Professor C, 2017).

Outro ponto de destaque foi sobre a questão do corpo. Este corpo que na entrada dos aquecimentos era mais problemático, ou melhor, mais difícil, por ser um corpo que dorme em uma cela, precisa ter um tempo maior de preparo pois fica enrijecido, frio, das camas de concreto. Ainda o Professor B (2017) falou: "Achava que a sexta seria só para o teatro, porque você poderia levar um pouco mais de tempo. Tem que entender qual a dinâmica de uma escola prisional. É diferenciada. Tanto que é coordenada por uma coordenadoria específica".

Nesse comentário, o Professor B tece uma crítica ao sistema em geral, pois ele acredita na necessidade de uma educação que vise o contexto social do ambiente carcerário, onde entrecruzam-se a "cultura prisional" e "cultura escolar” (VASQUEZ, 2013), mas que precisamos discutir e pensar na cultura artística.

Outra reflexão que escutamos ainda na reunião, foi a seguinte:

Tem professor tomando postura de agente e não de educador investigativo da percepção do agente. Você controla seu corpo na arte, e no momento de tensão, você sabe lidar porque lembra, porque está na pele. Seria interessante fazer um questionário com professores e alunas para perceber que o olhar do agente penitenciário é um olhar que não enxerga o ser humano, enxerga só o sistema penitenciário (Professor D, 2017).

Esta última contribuição abre espaço para debatermos sobre a realidade educacional e as suas relações de comunicação artística e prisional, no que tange o desenvolvimento humano e resolução de conflitos no ambiente carcerário. E para construção de olhar sensível, não só do educador, mas também do agente penitenciário, que tem uma postura regida pelo treinamento da disciplina. Por 
ser o servidor público, que não só treina para se proteger, mas para garantir a segurança dentro da prisão, dos servidores, da sociedade cativa e amapaense.

Contudo, necessita ser um trabalho que faça com que, as mulheres presas se sintam seguras, durante o cumprimento de suas sentenças criminais ou detenção provisória.

Mas falando sobre a experiência da atividade extensionista na prisão, um professor da EESJ disse: "Ouvi falar muito bem do projeto" (Professor E, 2017). Enquanto outra profesora falou: "Para elas é novo, muitas lá dentro querem fazer, falam que é interessante" (Professora F, 2017).

Aproveitando estas falas, o professor coordenador recordou que: “Teve uma estudante, que participou do teatro por conta de uma punição dada pelo agente penitenciário, de que era uma solução para ocupar à mente. Algo que gera uma questão, mas que não há impedimento nenhum porque leva à pessoa a conhecer e a se conhecer" (Professor C, 2017).

Com essas colocações, a coordenadora pedagógica da escola e os professores/as refletiram sobre como as mulheres presas e estudantes da EESJ podiam na busca pelo conhecimento do Teatro e Arte, desenvolver a observação e a interação social. E fizeram um convite para que estivesse presente, o representante do Grupo de Teatro, na semana pedagógica do próximo ano letivo.

A equipe do extensão universitária destacou a importância de defender um projeto como esse no espaço penitenciário, por entender que o corpo humano vai se aprisionando. As apenadas antes mal falavam e/ou movimentavam seus corpos, e em alguns meses, com os alongamentos, aquecimentos vocais, jogos e improvisação, elas perceberam que é possível uma transformação com e pela cultura artística.

A coordenadora pedagógica avaliou que: "Foi um ganho muito forte do teatro aqui, a relação delas com agente penitenciária, melhorou nos estudos. Antes elas pensavam apenas na cena (de teatro), mas, descobriram que era o conhecimento do corpo" (Professora G, 2017).

\subsection{Olhares docentes a partir de práticas pedagógicas em teatro}

O ensino de teatro para além da formação de atores, a coordenação de projetos à comunidade externa da UNIFAP, o teatro como ação sócio-cultural, o teatro na prisão e escola, são questões que atravessam os corpos dos professores, e nos levam para fora dos muros da universidade, com o intuito de difundir a cultura artística como direito de qualquer pessoa. 
O contato com corpos em privação de liberdade, a possibilidade de transgredir a lógica de instituições de controle, a liberdade que está sempre presente em toda e qualquer mente, mesmo que o corpo físico esteja enclausurado, o trabalho que parte apenas de uma premissa: o interesse pessoal. Participa quem quer! Sem remição de pena!

São fatores como estes que nos levaram ao sistema penitenciário na cidade de Macapá e que se tornam materiais para desenharem a trajetória do projeto. Os corpos pulsantes nos mostraram que o foco se dá na transposição do processo de aprendizagem em teatro à vida diária, sem que a confecção do produto seja algo primordial. Pontos como a vivência, com diferentes linguagens artísticas e a formação do expectador passam a ser novos caminhos nessa trajetória.

Nesse caminho, destacamos os corpos femininos que possuem trajetórias específicas e que lutam pela individualidade num espaço disciplinar. Alguns pontos geram conflitos internos: a estrutura de segurança da instituição e a sua lógica; a alternância de público; a religiosidade; o acordo e a confiança; a mulher que assume autoria de crimes realizados por seus companheiros.

Em outra direção desta trajetória, algumas descobertas: o teatro reverberando nos agentes penitenciários que observavam as aulas; a afetividade que ultrapassa a sexualidade; o corpo feminino x o corpo lgbt; a redescoberta de si por si mesmo(a), sendo o teatro o mediador deste processo educacional e artístico.

Algumas percepções inquietam nesta trajetória: a importância dos Direitos Humanos na manutenção da igualdade de oportunidades; a baixa escolaridade das apenadas em geral; o entendimento de que as mulheres não podem ser tratadas como homens nas prisões; o cuidado para com a saúde da mulher: menstruação/exames rotineiros/higiene; o teatro como exercício da cidadania perdida; o teatro e a educação de jovens e adultos no sistema prisional, entendidos como espaços de resistência para práticas educativas humanizadoras; a conscientização da relação opressor-oprimido por parte dos envolvidos no projeto; a necessidade de que todos e todas participantes, em suas diferentes posições, aprendam a se colocar no lugar da outra pessoa.

\section{EM BUSCA DE CONSIDERAÇÕES}

O texto centrou-se em apresentar um relato de experiência sobre as oficinas realizadas com mulheres presas que estavam custodiadas na Coordenadoria da Penitenciária Feminina, no Estado do Amapá, o que implicou em do- 
cumentar uma parte da criação em teatro no ambiente carcerário como uma ex perinência humana e que toma como referência a colocação de Larrosa (2008) citada por Ferreira (2016, p. 2): “A experiência é o que nos passa, ou o que nos acontece, ou o que nos toca. Não o que passa ou que acontece, ou que toca, mas o que nos passa, o que nos acontece ou nos toca".

Nesse contexto, consideramos que:

[...] o Teatro passa a ser uma possibilidade de o indivíduo retomar a relevância e a valorização de sua individualidade como algo que se constitui no encontro com o outro, além da autonomia perante suas escolhas e suas especificações, como um produto potencializador de identidades transgressoras (FERREIRA, 2016, p. 2-3).

As oficinas de teatro ofertadas no ambiente carcerário remetem-nos de algum modo a refletir sobre a experiência de transgressão, que pode aludir a aspectos negativos, como rebeldia, infração, violação e inobservância de normas, a qual é entendida na perspectiva da ação humana de atravessar e ultrapassar limites que solidificam a estrutura hierárquica na escola (FERREIRA, 2016).

O papel da Arte-Educação e no caso específico aqui descrito, o TeatroEducação promove a articulação da re-construção identitária dos agentes envolvidos e viabiliza a expressão cultural como fator de contextualização das questões sociais de apenadas, além do empoderamento através da vivência artística e a transposição do processo de aprendizagem à vida carcerária.

É na troca de saberes, nos encontros de trajetórias e na experimentação de oportunidades que a vida humana proporciona ou que proporcionamos às pessoas, que passamos a entender, a importância da trajetória de cada pele e como cada corpo humano é um espaço que precisa ser respeitado, revisitado e potencializado.

\section{REFERÊNCIAS}

ALBUQUERQUE, D. M. J. Michel Foucault e a Mona Lisa ou como escrever a história com um sorriso nos lábios. In: RAGO, M.; VEIGA-NETO, A.

(Org.). Figuras de Foucault. São Paulo: Autêntica, 2006.

BOAL, A. Jogos para atores e não atores. Rio de Janeiro: Civilização Brasileira, 1999. 
CONCÍLIO, V. Teatro e prisão: dilemas da liberdade artística em processos teatrais com população carcerária. 2006. Dissertação (Mestrado em Artes Cênicas) - Universidade de São Paulo, São Paulo, 2006.

ELIAS, N. A sociedade dos indivíduos. Rio de Janeiro: Zahar, 1994.

FERREIRA, F. C. Pedagogia palhacesca: uma poética de atravessamentos, transgressões e comicidade na escola básica. 2016. (Mestrado Profissional em Arte) - Universidade Federal de Uberlândia, Uberlândia, 2016.

FOUCAULT, M. Microfísica do poder. 2.ed. Rio de Janeiro: Graal, 1981.

. Vigiar e punir: nascimento da prisão. 20.ed. Trad. Raquel Ramalhete. Petrópolis: Vozes, 1999.

FREIRE, P. Pedagogia da autonomia. São Paulo: Ed. Paz e Terra, 1997.

Pedagogia do oprimido. São Paulo: Ed. Paz e Terra,1994

LARROSA, J. Desejo de Realidade: Experiência e alteridade na investigação educativa. In: BORBA, S.; KOHAN, W. (Org.). Filosofia, aprendizagem, experiência. Belo Horizonte: Autêntica, 2008.

LIGIERO, Z. Teatro a partir da comunidade. Rio de Janeiro: Papel Virtual Editora, 2003.

RESENDE, S. H. A vida na prisão: histórias de objeção e sujeição na educação do condenado. In: BOAL, A. Jogos para atores e não atores. Rio de Janeiro: Civilização Brasileira, 1999.

SPOLIN, V. Jogos teatrais para a sala de aula: um manual para o professor. Trad. I. D. Koudela. São Paulo: Perspectiva, 2007.

UNIVERSIDADE FEDERAL DO AMAPÁ. Catálogo de Extensão da Universidade Federal do Amapá. Macapá, 2019. Disponível em: < $\underline{\text { https:// }}$ www.yumpu.com/pt/document/read/62662567/catalogo-da-extensao-universidade-federal-do-amapa $>$. Acesso em: 15 jan. 2019.

VASQUEZ, E. L. Sociedade cativa. Entre cultura escola e cultura prisional: uma incursão pela ciência penitenciária. Rio de Janeiro: CBJE, 2013.

VEIGA, C. G. A escolarização como projeto de civilização. Revista Brasileira de Educação, Rio de Janeiro, n. 21, p. 90-170, Set./Dez. 2002. 
